\title{
Hypersensitivity Reactions to Platinum Agents and Taxanes
}

\author{
Lulu R. Tsao ${ }^{1}$ (D) Fernanda D. Young ${ }^{1} \cdot$ Iris M. Otani $^{1} \cdot$ Mariana C. Castells ${ }^{2}$
}

Accepted: 13 July 2021 / Published online: 2 August 2021

(c) The Author(s) 2021

\begin{abstract}
Hypersensitivity reactions (HSRs) to chemotherapy agents can present a serious challenge to treating patients with preferred or first-line therapies. Allergic reactions through an immunologic mechanism have been established for platinum and taxane agents, which are used to treat a wide variety of cancers including gynecologic cancers. Platin HSRs typically occur after multiple cycles of chemotherapy, reflecting the development of drug IgE sensitization, while taxane HSRs often occur on first or second exposure. Despite observed differences between platin and taxane HSRs, drug desensitization has been an effective method to reintroduce both chemotherapeutic agents safely. Skin testing is the primary diagnostic tool used to risk-stratify patients after initial HSRs, with more widespread use for platinum agents than taxanes. Different practices exist around the use of skin testing, drug challenge, and choice of desensitization protocol. Here, we review the epidemiology, mechanism, and clinical presentation of HSRs to platinum and taxane agents, as well as key controversies in their evaluation and management.
\end{abstract}

Keywords Chemotherapy $\cdot$ Hypersensitivity $\cdot$ Drug allergy $\cdot$ Desensitization $\cdot$ Platinum agent $\cdot$ Taxane

\section{Introduction}

More than 20 years ago, platinum agents and paclitaxel became the standard first-line regimens for treatment of ovarian cancer based on clinical trial data from the Gynecologic Oncology Group and European investigators [1]. Their increased use was accompanied by a relatively high prevalence of hypersensitivity reactions (HSRs) in women requiring repeated cycles of chemotherapy. Rapid drug desensitization (RDD) has allowed patients to continue receiving first-line treatments and avoid unnecessary switches to second- or third-line therapies that might be less effective or more toxic. Since the early 2000s, many institutions have implemented protocols for evaluation and treatment of patients with HSRs to chemotherapy agents. Along the way, there has been significant evolution in our understanding of both IgE-mediated and non-IgE-mediated reactions to these

Lulu R. Tsao

lulu.tsao@ucsf.edu

1 UCSF Department of Medicine, Division of Pulmonary, Critical Care, Allergy and Sleep Medicine, San Francisco, CA, USA

2 Brigham and Women's Hospital, Department of Medicine, Division of Allergy and Clinical Immunology, Boston, MA, USA drugs. Areas of active research include optimal risk stratification based on patient history, skin testing, and biomarkers, as well as the safety and efficacy of various desensitization protocols and strategies for delabeling.

\section{Clinical Presentation}

\section{Platinum Agents}

Carboplatin and cisplatin are commonly used for ovarian, lung, and head and neck cancers (Table 1) [2]. Carboplatinbased regimens are frequently recommended for women with platinum-sensitive recurrent ovarian cancer $[3,4]$. Oxaliplatin is commonly used in colorectal cancer regimens as first-line or adjuvant treatment for metastatic disease [5].

Reported incidence, indications, and clinical presentations of immediate HSRs to platinum agents are shown in Table 1. The incidence of carboplatin HSRs has been best described in gynecologic cancer, especially ovarian cancer, at rates of $8-16 \%$ [6-8]. Incidence among patients with other types of cancers is less well known. At one center, carboplatin HSR occurred in $7.9 \%$ of ovarian cancer patients and $2.6 \%$ of all cancer patients, including lung, head and neck, other gynecologic, and breast cancers [9]. However, when evaluated by total lifetime dose or number of cycles, incidence was similar regardless of cancer type [9]. 


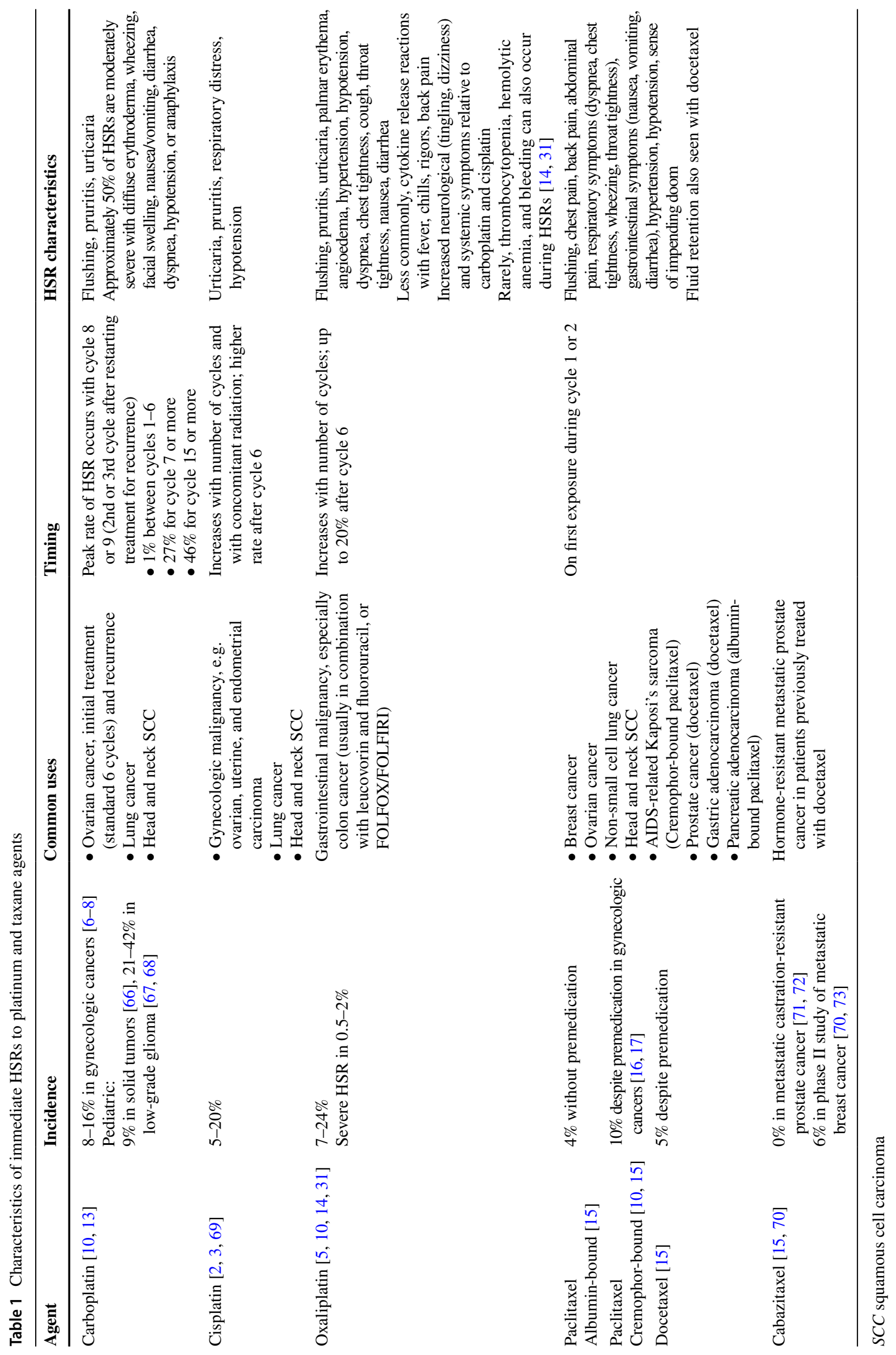


The main risk factor for platin HSR is prior treatment with these therapies [3]. The rate of carboplatin HSR increases from $1 \%$ during the first six cycles to $27 \%$ after 7 doses, and the peak rate occurs with cycle 8 or 9 , which usually corresponds to the second or third cycle after restarting treatment for recurrent disease [10]. Similar patterns have been seen with cisplatin and oxaliplatin $[2,3]$. Increased rates have also been observed in women with BRCA mutations [11] and with certain chemotherapy regimens. For example, in the CALYPSO study, women treated with carboplatin/paclitaxel had a higher incidence of HSR compared to carboplatin/doxorubicin regimens [12].

Platinum agents can cause type I reactions, cytokine release reactions, and mixed reactions, and mechanisms for each phenotype are shown in Fig. 1A. Evidence supporting an IgE-mediated mechanism for HSRs to platinum agents was first described in refinery workers exposed to platinum salts and subsequently with the detection of carboplatin-specific IgE [13]. Most reactions are immediate and occur during or within hours after infusion $[3,4]$. For oxaliplatin specifically, HSRs are more heterogeneous and include cytokine release reactions presenting with fevers, chills, rigors, headache, chest pain, and/or back pain along with elevated levels of IL-6 and TNF- $\alpha$ [5]. Oxaliplatin can also induce mixed reactions with symptoms of both type 1 hypersensitivity and cytokine release reactions [5]. This variability has motivated efforts to endophenotype oxaliplatin reactions to better predict outcomes with desensitization [5].
In contrast to carboplatin and cisplatin, cases of immunemediated hemolytic anemia and thrombocytopenia complicated by bleeding have also been reported for oxaliplatin [ 5 , 14]. Delayed rashes have been reported hours to days after carboplatin infusion, ranging in severity from mild reactions to skin desquamation [13]. There have not been any reports of Stevens-Johnson syndrome/toxic epidermal necrolysis (SJS/TEN), erythema multiforme, or serum sickness with carboplatin [10].

\section{Taxanes}

Taxane agents are used in the treatment of breast, gynecologic, prostate, head and neck, and lung cancers, and include paclitaxel, docetaxel, nab-paclitaxel, and cabazitaxel (Table 1) [15]. Paclitaxel (Taxol) was originally isolated from the bark of the Pacific yew tree, while docetaxel (Taxotere) was made from a semisynthetic process [15].

Similar to carboplatin, the incidence of HSR to paclitaxel has been best studied in gynecologic cancer [16, 17]. Initial studies found rates of immediate HSRs of up to $50 \%$ with paclitaxel and docetaxel infusions, resulting in the routine use of antihistamine and steroid premedication [15, 18, 19]. Incidence rates, indications, and clinical presentations of immediate HSRs for taxanes are presented in Table 1. Immediate HSRs to paclitaxel and docetaxel occur in approximately $10 \%$ of patients despite premedication and are severe in $1 \%[10,18]$. They commonly occur within minutes during

a
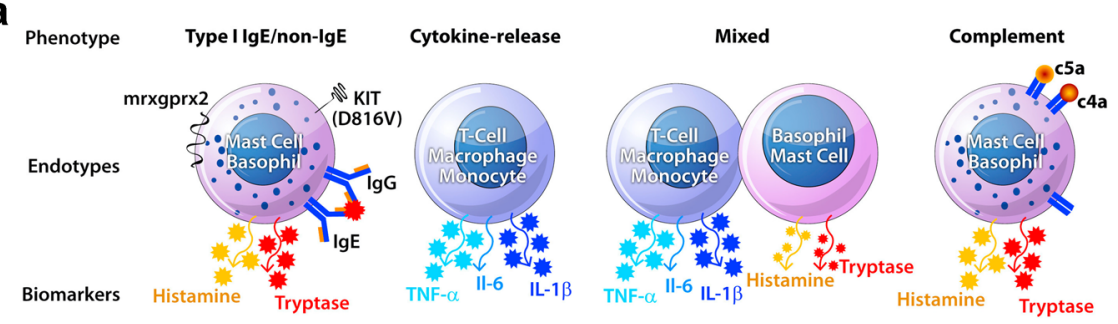

b
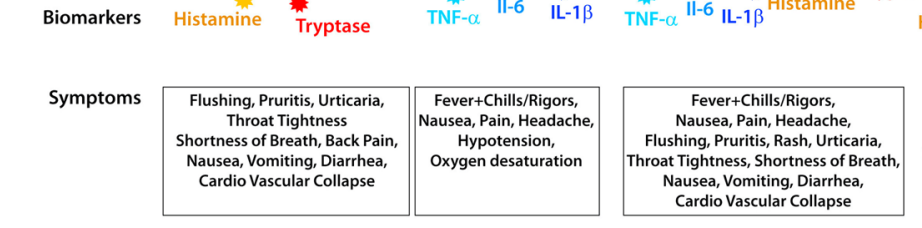

Hypotension Oxygen desaturation

Treatment Epinephrine

Desensitization
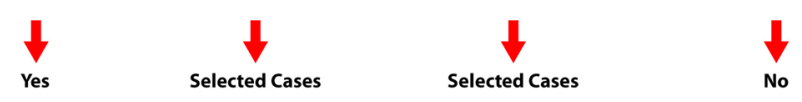

Fig. 1 Mechanisms of immediate HSRs to platins and taxanes. Phenotypes of platin HSRs include type I reactions, cytokine release reactions, and mixed reactions, with the most heterogeneity seen with oxaliplatin (A). Taxanes may cause mast cell and/or basophil activation through IgE-mediated mechanisms, direct action on basophils, or IgGmediated mechanisms that cause complement activation and release of anaphylatoxins (C3a, C5a) (A, B). Solvents for taxanes, such as Cremophor EL (paclitaxel) and polysorbate 80 (docetaxel), may also acti- vate mast cells through an IgE-mediated mechanism or direct complement activation. Biomarkers include tryptase, histamine, leukotrienes, and prostaglandins in type I reactions and IL- 6 , TNF- $\alpha$, and IL- $1 ß$ in cytokine release or mixed reactions $(\mathbf{A}, \mathbf{B})$. Desensitization is indicated for type I reactions and selected cases of cytokine release and mixed reactions, but not in direct mast cell/basophil activation (A). LTC4 leukotriene C4, PGD2 prostaglandin D2. Reproduced from Fig. 1 in Castells [65] and Fig. 3 in Picard and Castells [15] with permission 
the first or second lifetime exposure, with symptoms such as flushing, dyspnea, throat tightness, hypotension, as well as more atypical symptoms like chest or back pain $[18,19]$. Delayed rashes have also been reported hours to weeks after infusion $[3,10]$. Severe reactions such as SJS/TEN, acute interstitial pneumonitis, and subacute cutaneous lupus erythematous have been described in case reports with paclitaxel, docetaxel, and nab-paclitaxel $[10,15]$.

Potential mechanisms for immediate taxane HSRs are shown in Fig. 1B. Due to the timing of reaction with first or second exposure, the mechanism has been thought to be nonIgE-mediated in some cases and possibly related to infusion solvents, although initial data indicated that a majority of patients were allergic and cross-reactivity with tree pollen allergens was suggested [20]. Cremophor EL in paclitaxel and polysorbate 80 in docetaxel and cabazitaxel are solubilizing and emulsifying agents that can cause complement activation with anaphylatoxin production and mast cell activation in vitro $[15,18]$. Polysorbate 80 may also cause direct mast cell activation via peroxide formation [21]. Data supporting the role of Cremophor includes the decreased rate of immediate HSRs with nanoparticle albumin-bound paclitaxel (nab-paclitaxel), with no reactions seen in phase I, II, or III studies despite omitting premedication [22-24]. Nevertheless, severe immediate HSRs have still been reported with nab-paclitaxel in post-marketing surveillance [15]. More recently, IgE-mediated mechanisms for at least a subset of taxane HSRs have been suggested based on positive skin test results and immunoblot assays [15]. One postulated mechanism for the occurrence of IgE-mediated taxane HSRs during initial cycles is that patients living in parts of the world with yew trees may be sensitized by pollen exposure [15]. Paclitaxel has also been isolated from hazelnuts [25], and hypersensitivity reactions to both paclitaxel and hazelnut ingestion have been described [26]. Other suggested mechanisms include histamine release through a direct effect of paclitaxel on basophils [15].

\section{Classification and Grading of HSRs}

Multiple classification systems exist to describe HSR severity. This has important implications as initial HSR severity has been used to guide treatment decisions such as rechallenge and choice of desensitization protocol [27, 28]. It also contributes to the challenge of comparing and contrasting published findings that use different grading systems.

The most commonly used classifications include Brown's grading system and the Common Terminology Criteria for Adverse Events (CTCAE) (Table 2). The Brown classification incorporates specific elements of HSRs and severity of organ involvement used by allergists, while CTCAE focuses on the duration of reaction and interventions required. The CTCAE is a National Cancer Institute (NCI) classification system for chemotherapy adverse event reporting and grades infusion reactions based on severity [29]. The Brown grading system was originally created for a wide range of HSRs and is not specific to chemotherapy agents or even drug allergy. It is based on the association of specific symptoms with severe reactions, such as hypotension and hypoxia, among 1149 patients presenting to an ED with HSRs [30]. When applied to chemotherapy agents, Brown grade 1 (mild) reactions would be limited to the skin or involve a single organ system, grade 2 (moderate) reactions involve 2 or more organ systems without a significant decrease in blood pressure or oxygen saturation, and grade 3 (severe) reactions include vital sign changes such as hypotension, oxygen desaturation, and cardiovascular collapse [31, 32].

\section{Role of Skin Testing}

Skin testing (ST) is the most widely used diagnostic tool in the evaluation and risk stratification of platin and taxane HSRs, although specific IgE (sIgE), basophil activation test (BAT), and other biomarkers such as soluble FceRI and total IgE have also been studied [33-35].

\section{Platinum Agents}

Carboplatin skin testing was first developed in the 1990s and has been increasingly used in the evaluation and management of carboplatin HSRs [13]. However, differences in practice remain, with some institutions using serial ST for risk stratification $[36,37]$ and others not using ST at all [28]. The negative predictive value (NPV) of a single intradermal test for carboplatin has been estimated at 81-92\% [13]. Accurate estimates of positive predictive value (PPV) are limited by the ethical issues of challenging patients after a positive ST. However, in one study, 6 of 7 ST-positive patients experienced an HSR with standard infusion, thus providing a PPV of $86 \%$ [38]. For oxaliplatin, a recent study did not find any association between skin testing and breakthrough reactions [5], whereas a separate study of 74 oxaliplatin-reactive patients reported sensitivity and specificity of $57.5 \%$ and $91.7 \%$, respectively [33]. There is a need for additional studies and rigorous study designs to assess predictive values of ST.

\section{Concentrations}

Reported nonirritating concentrations for platinum skin testing are shown in Table 3. The intradermal test (IDT) is 


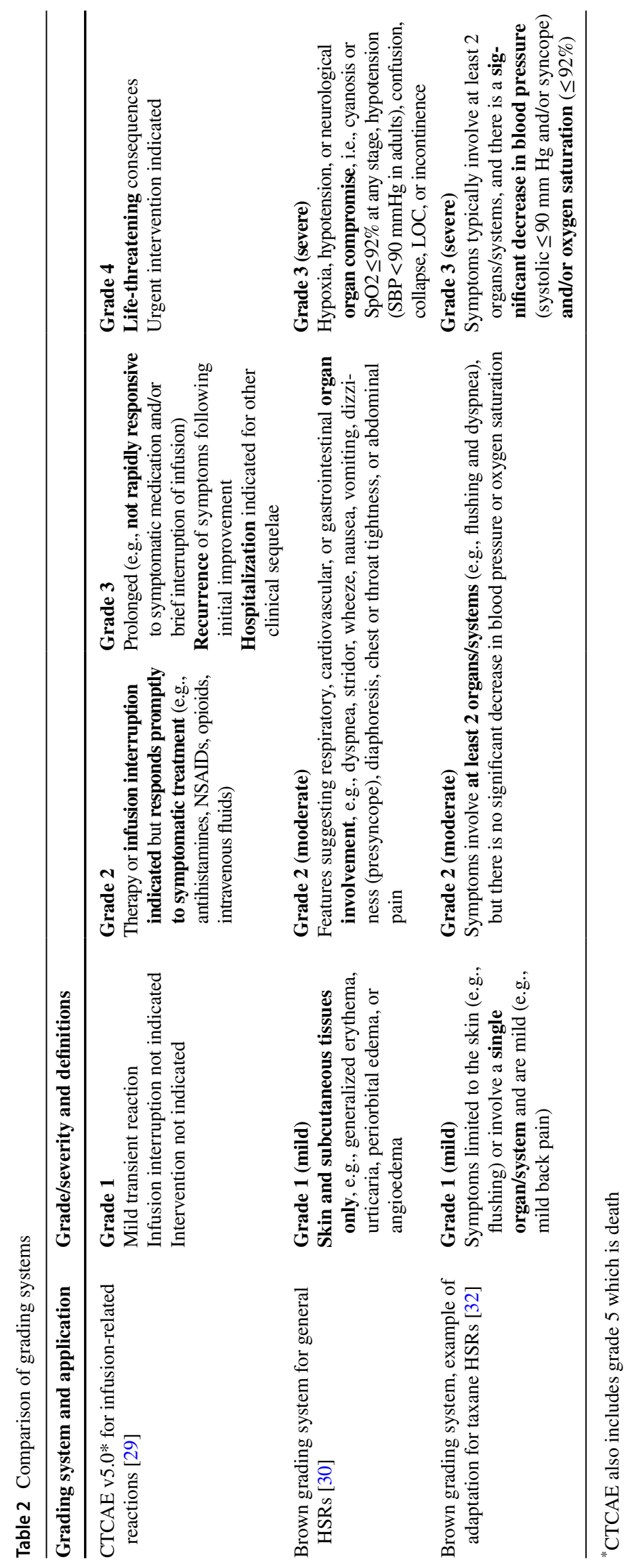


Table 3 Nonirritating concentrations for platinum agent skin testing

\begin{tabular}{lll}
\hline Agent & SPT dilutions $(\mathbf{m g} / \mathbf{m L})$ & $\begin{array}{l}\text { IDT dilutions } \\
(\mathbf{m g} / \mathbf{m L})^{\mathrm{a}}\end{array}$ \\
\hline Carboplatin & 10 & 0.1 \\
& & 1 \\
Oxaliplatin & 5 & $5^{\mathrm{b}}$ \\
& & 0.05 \\
Cisplatin & 1 & 0.5 \\
& & 5 \\
& & 0.01 \\
& & 0.1 \\
\end{tabular}

Variations exist: the European Academy of Allergy and Clinical Immunology (EAACI) recommends concentrations of 10 and $1 \mathrm{mg} /$ $\mathrm{mL}$ for carboplatin SPT and IDT and 1 and $0.1 \mathrm{mg} / \mathrm{mL}$ for oxaliplatin and cisplatin SPT and IDT [73]

$S P T$ skin prick test, $I D T$ intradermal test

${ }^{\text {a }}$ For intradermal tests, $0.02-0.03 \mathrm{~mL}$ is used

${ }^{b}$ Reported concentrations for the last IDT step include 3, 5, and $10 \mathrm{mg} / \mathrm{mL} ; 10 \mathrm{mg} / \mathrm{mL}$ has been reported to cause local skin necrosis and is therefore not recommended

needed to achieve adequate sensitivity, as $86.4 \%$ of positive carboplatin ST are identified by intradermal testing [13]. The concentration used for testing affects the predictive value of ST. Lower concentrations of $1-5 \mathrm{mg} / \mathrm{mL}$ have resulted in positive ST for $41-75 \%$ of patients, whereas a final intradermal concentration of $10 \mathrm{mg} / \mathrm{mL}$ has resulted in positive ST for $81-88 \%$ [13]. However, higher concentrations (10 mg/ $\mathrm{mL}$ ) of carboplatin and oxaliplatin are generally avoided as they can cause irritation and are associated with a risk of skin necrosis and subsequent scarring $[4,10,36]$.

\section{Timing}

The length of time between ST and prior carboplatin exposure or HSR is also important in the interpretation. Based on data from hymenoptera venom skin testing data and the risk of false negatives due to anergy, it is generally recommended that skin testing be performed at least 4 to 6 weeks after the initial HSR [2, 13]. Some recent studies have reported using a window of 2 weeks [5, 39]. However, false negatives may result. In one of these studies, 5/37 (13.5\%) ST-negative patients who had been tested within 10 days of an immediate HSR to platinum agents developed recurrent reactions and subsequently converted to ST-positive [39].

There are also higher rates of false-negative ST if performed more than 6 months after initial carboplatin and oxaliplatin HSR, which suggests waning of ST reactivity over time. These patients may undergo conversion from ST-negative to ST-positive after their first desensitization $[4,14,36,37]$. In early studies, $12 / 23(52 \%)$ of carboplatin initial ST-negative patients and 2/21 (10\%) of oxaliplatin initial ST-negative patients were found to convert to STpositive on serial ST $[14,36]$, and repeat skin testing protocols for risk stratification were developed to identify "ST converters."

\section{Uses and Patient Population}

ST has been primarily used as a risk stratification tool to guide choice of desensitization protocol after HSR and identify patients who may be able to eventually transition to faster infusions. Less common uses for ST include identification of sensitized individuals before the occurrence of HSR and identification of patients who can undergo reintroduction via drug provocation testing, which is discussed further in the next section.

Use of serial ST for risk stratification in a platin HSR pathway has been described, where ST-positive patients underwent intermediate 12-step desensitization while STnegative patients underwent rapid 8-step desensitization, both in the inpatient setting [37]. If patients had 3 negative ST results, they were advanced to $50 \%$ infusion rate inpatient and, if no reaction, $50 \%$ infusion rate outpatient.

To decrease time and resource needs, a modified intradermal 1-step skin test protocol using only the highest concentration was recently reported for low-risk patients with platin HSRs [40]. These were patients who had tolerated prior intermediate desensitization without an HSR and did not have a history of positive ST. In a pilot study, $8 / 10(80 \%)$ patients had a negative ID test and $6 / 10(60 \%)$ were ultimately converted to $50 \%$ infusion rate outpatient [40]. Of note, this 1-step protocol has not been studied for use after initial HSR and is not yet recommended in that setting.

\section{Taxanes}

Skin testing has not been as routinely performed for taxanes because the mechanism of HSRs was traditionally thought to be non-IgE-mediated [20, 41]. However, as discussed previously, a subset of patients may react via an IgE-mediated process based on prior sensitization to a cross-reactive pollen from the yew tree [42]. ST has been reported for paclitaxel and, to a more limited extent, docetaxel [19, 32, 33, 39], but not cabazitaxel or nab-paclitaxel [10].

\section{Concentrations}

Table 4 shows concentrations that have been reported for skin prick and intradermal testing. Taxane ST was the focus of a multicenter study that used skin prick 
concentrations of $6 \mathrm{mg} / \mathrm{mL}$ and $1 \mathrm{mg} / \mathrm{mL}$, and intradermal concentrations of $0.06 \mathrm{mg} / \mathrm{mL}$ and $0.01 \mathrm{mg} / \mathrm{mL}$, for paclitaxel and docetaxel, respectively [19]. In 84 patients with a history of immediate HSRs to taxanes, skin prick testing was negative in all patients, whereas intradermal testing was positive in 14 patients (16.7\%), 10 to paclitaxel and 4 to docetaxel. ST were negative in 30 control patients exposed to taxanes without HSRs. This study reported a sensitivity of $16.7 \%$ (95\% CI, 8.7-24.6\%) and specificity of $100 \%$ for taxane ST. A larger study by Picard et al. reported ST results from 145 patients using skin prick concentrations of $1 \mathrm{mg} / \mathrm{mL}$ and $0.4 \mathrm{mg} / \mathrm{mL}$ for paclitaxel and docetaxel, respectively, and intradermal concentrations of 0.001 and $0.01 \mathrm{mg} / \mathrm{mL}$ for paclitaxel and 0.04 and $0.4 \mathrm{mg} / \mathrm{mL}$ for docetaxel. Of 138 paclitaxel ST performed, 5 (4\%) were positive on skin prick and $92(67 \%)$ on intradermal test, while none of the 9 docetaxel ST were positive on skin prick and $8(89 \%)$ were positive on intradermal test [32]. In both studies, positive skin tests correlated with grade 3 reactions and cutaneous symptoms, such as flushing [19, 32]. Differences in initial HSR severity or yew sensitization due to geographical area may explain the observed differences in skin test positivity rates [19].

\section{Timing}

ST conversion from negative to positive with taxanes has been infrequently reported compared to platins. In the study of 145 patients who underwent taxane ST, one patient $(0.7 \%)$ converted [32]. Her initial HSR was a delayed maculopapular rash to paclitaxel and ST was negative. She subsequently tolerated 1 challenge and 3 regular infusions before experiencing an immediate grade 3 HSR and converting to ST-positive on re-evaluation.

\section{Uses and Patient Population}

One potential use for taxane skin testing is the identification of patients who have infusion reactions but may not need desensitization [42]. This relates to the non-IgE mechanisms postulated for taxane HSRs, as reactions to solvents like Cremophor may be idiosyncratic and not recur on re-exposure. Picard et al. used taxane ST as part of risk stratification to identify 36/164 (22\%) patients who could undergo drug challenges and eventually return to standard infusion without need for desensitization [32].

\section{Role of Drug Provocation Testing}

There is debate regarding the role of a diagnostic drug challenge or drug provocation testing (DPT) after an initial HSR to platinum and taxane agents [21].

For platinum agents in particular, prior observational data have shown that there can be high rates of recurrent HSR, including severe HSR, when patients are rechallenged without desensitization. In an early study, symptoms recurred in all 32 patients with carboplatin HSRs who were rechallenged, and 12 patients (38\%) discontinued treatment due to severe reactions [7]. Another oncology center rechallenged 14/27 (52\%) patients with oxaliplatin HSR, and 4/14 (29\%) developed recurrent HSR despite steroid and antihistamine premedication, of which two were CTCAE grades 3-4 [43]. As a result, there has been reluctance to rechallenge patients with platin HSRs. Success rates for rechallenge may be higher for taxane HSRs. A prior observational study found that patients with a history of paclitaxel HSR were more likely to tolerate rechallenge than those with platin HSRs [44]. In addition, as mentioned above, Picard et al. developed a risk stratification approach to rechallenge patients with delayed or grade 1-2 immediate HSRs who had negative ST using a 3-step challenge protocol [32].

Nevertheless, certain institutions in Europe have protocolized the use of DPT for chemotherapy agents and biologics [33, 45-47]. A group reported on 7 years of experience with 102 challenges to taxanes and 93 challenges to platins, which allowed 70 and 43 patients, respectively, to continue treatment without desensitization [45]. These DPTs were performed by administering these agents at standard infusion rates according to manufacturer instructions with only standard premedications [33]. If there were multiple potential culprits (including premedications or concomitant drugs in the

Table 4 Reported taxane skin testing protocols

\begin{tabular}{lllllll}
\hline Reference & Agent & $\begin{array}{l}\text { SPT dilutions } \\
(\mathbf{m g} / \mathbf{m L})\end{array}$ & IDT dilutions (mg/mL) & $\begin{array}{l}\text { No. of patients } \\
\text { with ST }\end{array}$ & SPT positive & IDT positive \\
\hline Picard et al. (2016) [32] & Paclitaxel & 1 & $0.001,0.01$ & 138 & $5(4 \%)$ & $92(67 \%)$ \\
& Docetaxel & 0.4 & $0.04,0.4$ & 9 & 0 & $8(89 \%)$ \\
Pagani et al. (2019) [19] & Paclitaxel & 6 & 0.06 & 63 & 0 & $10(16 \%)$ \\
& Docetaxel & 1 & 0.01 & 21 & 0 & $4(19 \%)$ \\
\hline
\end{tabular}

Published skin testing dilutions for skin prick and corresponding intradermal tests from the two largest studies are shown. Protocols have not been compared for different patient characteristics. There were more patients with ovarian cancer and prostate cancer in Picard et al. [32], while breast cancer was the most common cancer in Pagani et al. [19] 
regimen, such as leucovorin), DPT was performed for each suspect medication $[33,45]$. Severe reactions occurred in up to $7 \%$ of the patients who underwent either platin or taxane DPT [45], and the authors emphasize that while DPT can be used as a diagnostic tool with careful patient selection and risk assessment, it is a high-risk procedure that requires specialized resources, monitoring, and expert allergy care [21].

Patients selected for DPT had a history of HSR occurring within $48 \mathrm{~h}$ of drug administration and were considered low or medium risk for true HSR. Risk assessment was based on patient-related factors such as comorbidities and acute illness; the drug being administered; prior reaction history, including severity, timing, and need for interventions; and results of ST, sIgE, and other biomarkers if available (e.g., tryptase, IL-6, BAT) [33, 45, 46]. DPT was not performed for patients with delayed reactions or SCARs (such as vasculitis, SJS/TEN, drug-induced hypersensitivity syndrome); previous severe reactions (such as a history of intubation and cardiovascular collapse); high-risk comorbidities (such as uncontrolled asthma, unavoidable use of $\beta$-blockers, critical illness, acute infections); or pregnant patients $[33,45,48]$.

A DPT was considered positive if it reproduced the original symptoms or objective findings of HSR [33]. Once symptoms were treated and the patient was asymptomatic, a "restart protocol" was used, beginning at 25\% standard rate for $15 \mathrm{~min}$ and increased to $50 \%$ standard rate until completion $[33,45]$. Patients with positive DPT subsequently underwent desensitization. Patients with a negative DPT subsequently underwent standard infusion [33, 45].

The severity of HSRs in patients who underwent DPT in these studies is an important factor that should be examined. In the largest report, the majority of 188 patients with platin HSRs had mild-to-moderate initial HSRs: $42 \%$ grade 1, 34\% grade 2 , and $24 \%$ grade 3, using the Brown system [45]. After further risk stratification, 93 of 188 (49\%) underwent DPTs, of which $50(54 \%)$ were positive and $7(14 \%)$ of those were grade 3. In line with prior observational findings, more patients tolerated DPTs to taxanes than platins. Of 135 patients referred for taxane HSRs, the initial severity was grade 1 in $20 \%$, grade 2 in 54\%, and grade 3 in 26\% [45]. One hundred two (76\%) were deemed appropriate for DPTs, of which $32(31 \%)$ were positive and $7(22 \%)$ of those were grade 3 reactions.

These initial HSR severity profiles should be compared with other large studies of desensitizations, in which up to $80 \%$ (81/101) of initial HSRs were considered severe (characterized by the presence of chest pain, change in blood pressure, dyspnea, oxygen desaturation, or throat tightness), or up to $52 \%(205 / 395)$ were Brown grade $3[31,41]$. Similarly, in a 2015 report of 92 patients with carboplatin HSRs and 50 patients with oxaliplatin HSRs, the median initial HSR grade was 3 [37]. The majority of patients in these studies had positive ST results [31, 37, 41]. DPT would not be appropriate in these settings, although it may be considered in selected cases, such as in patients with grade 1 reactions and negative ST.

\section{Desensitization Protocols}

Rapid drug desensitization has become the standard of care for patients with platinum and taxane agent HSRs since the early 2000s. Since then, various protocols have been utilized to reintroduce these agents following a reaction. Key differences in desensitization protocols include the number of dilutions and rates of administration.

\section{Platinum Agents}

The most widely accepted desensitization protocol for platinum agents is a 12-step protocol using 3 dilutions (1:100, $1: 10,1: 1)$ with a 2 - to 2.5 -fold increase between consecutive steps based on in vitro mechanisms of mast cell $\mathrm{IgE}$ desensitization (Table 5) $[49,50]$. The successful use of a 6-h, 3-bag, 12-step carboplatin desensitization protocol was originally reported in gynecologic oncology patients with the first series of 10 patients who underwent 35 desensitizations, of which 31 (89\%) were completed without reaction and the remaining four involved mild cutaneous reactions that did not prevent completion [51]. In 2008, a larger case series of 413 chemotherapy desensitizations using the 12-step protocol was published, including 212 to carboplatin, 12 to cisplatin, and one to oxaliplatin [41]. Two thirds of desensitizations occurred without reaction; another $27 \%$ were mild cutaneous reactions requiring only antihistamine, and all breakthrough reactions were less severe than initial HSRs. As most reactions occur during the last step, the addition of a $60 \mathrm{~mL} / \mathrm{h}$ step between steps 11 and 12 has also been used $[2,10]$.

Depending on risk stratification, protocols with different number of dilutions can be utilized. Studies have found that patients with an initial negative carboplatin skin test result can tolerate a "rapid" 2-bag, 8-step protocol (Table 6) $[4,10,36,37]$. For high-risk patients with initial severe reactions or breakthrough reactions during intermediate desensitization, a "prolonged" 4-bag, 16-step protocol can be used (Table 7) [52]. Similar rapid, intermediate, and prolonged protocols have been published for oxaliplatin $[5$, $10,14]$.

In the largest published report to date of 2177 desensitizations to chemotherapy and monoclonal antibodies, 1069 carboplatin desensitizations were conducted using these protocols, of which $68 \%$ had no breakthrough HSR, $24 \%$ were mild, $4 \%$ were moderate, and $4 \%$ were severe without any deaths and with all patients being able to complete their treatment [31]. In other published studies, the percentage of patients experiencing a breakthrough 
Table 5 Twelve-step desensitization protocol for carboplatin total dose $600 \mathrm{mg}$

\begin{tabular}{|c|c|c|c|c|c|c|}
\hline & Volume (mL) & Concentration (mg/mL) & Amount infused (mL) & Total mg per bag & & \\
\hline Solution 1 & 250 & 0.024 & 9.38 & 6 & & \\
\hline Solution 2 & 250 & 0.24 & 18.75 & 60 & & \\
\hline Solution 3 & 250 & 2.38 & 250 & 595.27 & & \\
\hline Step & Solution & Rate $(\mathbf{m L} / \mathbf{h})$ & Time (min) & $\begin{array}{l}\text { Volume infused per } \\
\text { step }(\mathrm{mL})\end{array}$ & Dose per step (mg) & $\begin{array}{r}\text { Cumulative } \\
\text { dose (mg) }\end{array}$ \\
\hline 1 & 1 & 2.5 & 15 & 0.63 & 0.015 & 0.015 \\
\hline 2 & 1 & 5 & 15 & 1.25 & 0.03 & 0.045 \\
\hline 3 & 1 & 10 & 15 & 2.5 & 0.06 & 0.11 \\
\hline 4 & 1 & 20 & 15 & 5 & 0.12 & 0.23 \\
\hline 5 & 2 & 5 & 15 & 1.25 & 0.3 & 0.53 \\
\hline 6 & 2 & 10 & 15 & 2.5 & 0.6 & 1.13 \\
\hline 7 & 2 & 20 & 15 & 5 & 1.2 & 2.33 \\
\hline 8 & 2 & 40 & 15 & 10 & 2.4 & 4.73 \\
\hline 9 & 3 & 10 & 15 & 2.5 & 5.95 & 10.68 \\
\hline 10 & 3 & 20 & 15 & 5 & 11.91 & 22.58 \\
\hline 11 & 3 & 40 & 15 & 10 & 23.81 & 46.39 \\
\hline 12 & 3 & 80 & 174.38 & 232.5 & 553.61 & 600 \\
\hline
\end{tabular}

Solution 1 is a 100-fold dilution of the final target concentration; solution 2 is a tenfold dilution of the final target concentration, and the concentration of solution 3 is calculated by subtracting the cumulative dose administered in steps $1-8$ from the total target dose and dividing by the bag volume. Values shown are rounded to the nearest 2 decimal places

HSR during rapid and intermediate protocols for carboplatin and oxaliplatin ranges from 35 to $59 \%$ (Table 8 ), with higher rates in ST-positive (37-79\%) and ST converter (34-83\%) patients compared to ST-negative patients (9-55\%) [4, 36, 37, 53, 54]. As most breakthrough HSRs are mild, $97-100 \%$ of desensitizations in these studies were able to be completed, with less than $1-2 \%$ resulting in severe HSRs.

\section{Taxanes}

Similar rapid (2-bag, 8-step), intermediate (3-bag, 12-step), and prolonged (4-bag, 16-step) desensitization protocols have been published for taxanes [10,27, 32]. The successful use of a 12-step desensitization for paclitaxel and docetaxel was first published in a series of 17 gynecologic oncology patients who underwent 77 desensitizations [20]. In the large desensitization

Table 6 Eight-step desensitization protocol for carboplatin total dose $600 \mathrm{mg}$

\begin{tabular}{|c|c|c|c|c|c|c|}
\hline & Volume (mL) & Concentration $(\mathrm{mg} / \mathrm{mL})$ & $\begin{array}{l}\text { Amount infused } \\
(\mathrm{mL})\end{array}$ & Total mg per bag & & \\
\hline Solution 1 & 250 & 0.24 & 18.75 & 60 & & \\
\hline Solution 2 & 250 & 2.38 & 250 & 595.5 & & \\
\hline Step & Solution & Rate (mL/h) & Time (min) & $\begin{array}{r}\text { Volume infused } \\
\text { per step }(\mathrm{mL})\end{array}$ & Dose per step (mg) & $\begin{array}{r}\text { Cumulative } \\
\text { dose (mg) }\end{array}$ \\
\hline 1 & 1 & 5 & 15 & 1.25 & 0.3 & 0.3 \\
\hline 2 & 1 & 10 & 15 & 2.5 & 0.6 & 0.9 \\
\hline 3 & 1 & 20 & 15 & 5 & 1.2 & 2.1 \\
\hline 4 & 1 & 40 & 15 & 10 & 2.4 & 4.5 \\
\hline 5 & 2 & 10 & 15 & 2.5 & 5.96 & 10.46 \\
\hline 6 & 2 & 20 & 15 & 5 & 11.91 & 22.37 \\
\hline 7 & 2 & 40 & 15 & 10 & 23.82 & 46.19 \\
\hline 8 & 2 & 80 & 174.38 & 232.5 & 553.81 & 600 \\
\hline \multicolumn{7}{|c|}{ Total time $(\min )=279.38=4.66 \mathrm{~h}$} \\
\hline
\end{tabular}

Solution 1 is a tenfold dilution of the final target concentration. The concentration of solution 2 is calculated by subtracting the cumulative dose administered in steps 1-4 from the total target dose and dividing by the bag volume. Values shown are rounded to the nearest 2 decimal places 
Table 7 Sixteen-step desensitization protocol for carboplatin total dose $600 \mathrm{mg}$

\begin{tabular}{|c|c|c|c|c|c|c|}
\hline & Volume (mL) & Concentration (mg/mL) & Amount infused (mL) & Total mg per bag & & \\
\hline Solution 1 & 250 & 0.0024 & 9.38 & 0.6 & & \\
\hline Solution 2 & 250 & 0.024 & 9.38 & 6 & & \\
\hline Solution 3 & 250 & 0.24 & 18.75 & 60 & & \\
\hline Solution 4 & 250 & 2.38 & 250 & 595.25 & & \\
\hline Step & Solution & Rate (mL/h) & Time (min) & $\begin{array}{c}\text { Volume infused } \\
\text { per step }(\mathbf{m L})\end{array}$ & $\begin{array}{l}\text { Dose per step } \\
\quad(\mathrm{mg})\end{array}$ & $\begin{array}{r}\text { Cumulative } \\
\text { dose (mg) }\end{array}$ \\
\hline 1 & 1 & 2.5 & 15 & 0.63 & 0.0015 & 0.0015 \\
\hline 2 & 1 & 5 & 15 & 1.25 & 0.003 & 0.0045 \\
\hline 3 & 1 & 10 & 15 & 2.5 & 0.006 & 0.011 \\
\hline 4 & 1 & 20 & 15 & 5 & 0.012 & 0.023 \\
\hline 5 & 2 & 2.5 & 15 & 0.63 & 0.015 & 0.038 \\
\hline 6 & 2 & 5 & 15 & 1.25 & 0.03 & 0.068 \\
\hline 7 & 2 & 10 & 15 & 2.5 & 0.06 & 0.13 \\
\hline 8 & 2 & 20 & 15 & 5 & 0.12 & 0.25 \\
\hline 9 & 3 & 5 & 15 & 1.25 & 0.3 & 0.55 \\
\hline 10 & 3 & 10 & 15 & 2.5 & 0.6 & 1.15 \\
\hline 11 & 3 & 20 & 15 & 5 & 1.2 & 2.35 \\
\hline 12 & 3 & 40 & 15 & 10 & 2.4 & 4.75 \\
\hline 13 & 4 & 10 & 15 & 2.5 & 5.95 & 10.70 \\
\hline 14 & 4 & 20 & 15 & 5 & 11.91 & 22.61 \\
\hline 15 & 4 & 40 & 15 & 10 & 23.81 & 46.42 \\
\hline 16 & 4 & 80 & 174.38 & 232.5 & 553.58 & 600 \\
\hline \multicolumn{7}{|c|}{ Total time $(\mathrm{min})=399.38=6.66 \mathrm{~h}$} \\
\hline
\end{tabular}

Solution 1 is a 1000-fold dilution of the final target concentration; solution 2 is a 100-fold dilution of the final target concentration; solution 3 is a tenfold dilution of the final target concentration, and the concentration of solution 4 is calculated by subtracting the cumulative dose administered in steps 1-12 from the total target dose and dividing by the bag volume. Values shown are rounded to the nearest 2 decimal places. Note for Tables 5, 6, and 7: the total volume and dose dispensed are more than the final dose given to the patient because many of the solutions are not completely infused

study by Sloane et al. referenced above, paclitaxel was the drug with the lowest rate of reactions ( $15 \%$ of desensitizations), and only $2 \%$ of breakthrough HSRs were severe [31]. The percentage of patients experiencing an immediate breakthrough HSR in other studies has been reported at 21-30\% (Table 9), and one also observed delayed breakthrough HSRs in $14 \%$ of patients $[27,32,53]$. Atopy, but not initial HSR severity or ST result, was found to be associated with increased risk of immediate HSR during desensitization or challenge [32].

As can be seen, there are a number of different desensitization protocols that are variations on the theme of gradual uptitration from very low starting doses. These protocols can be further individualized if a patient experiences breakthrough HSRs by adding or modifying steps or premedications. Protocols utilized may also depend on the equipment and resources available at each institution.

Of note, premedications vary significantly between desensitization protocols, and there are limited data available on optimal premedication regimens. Different protocols may incorporate $\mathrm{H} 1$ antihistamines, $\mathrm{H} 2$ blockers, steroids, montelukast, and/or aspirin and other COX-1 inhibitors. These differences must also be taken into account when evaluating desensitization outcomes.

\section{One-Bag Protocols}

In addition to these multi-bag desensitization protocols, onebag desensitization protocols have been published, although their use has not been validated. At some institutions, a onebag protocol at standard concentration may be chosen for feasibility of preparation or in response to concerns about stability at lower dilutions [28]. Protocols ranging from 9 to 17 steps have been described for platins and taxanes in small patient cohorts ( $n=30-49$ for platins, $n=24-25$ for taxanes) [28, 55-58]. Again, the severity of initial HSRs is an important factor to consider, as the percentage of initial grade 3 HSRs varied from 10 to $25 \%$ for platins [55, 56 , $58]$ and 16 to $38 \%$ for taxanes $[55,57]$ in these studies. The percentage of patients experiencing breakthrough HSR with these one-bag protocols ranges from 27 to $61 \%$ for platins (with up to 6-8\% requiring epinephrine or not being able to complete desensitization) $[55,58]$ and lower for taxanes. 
Table 8 Breakthrough reactions in patients undergoing platin desensitization

\begin{tabular}{|c|c|c|c|c|c|c|}
\hline Study & Agent & $\begin{array}{l}\text { No. of steps in } \\
\text { desensitiza- } \\
\text { tion }\end{array}$ & $\begin{array}{l}\text { No. of desensitiza- } \\
\text { tions completed }\end{array}$ & No. of patients with BTR & $\begin{array}{l}\text { Severe BTR, n (\% } \\
\text { desensitizations) }\end{array}$ & $\begin{array}{l}\text { No. of patients unable } \\
\text { to complete treatment } \\
\text { due to BTR }\end{array}$ \\
\hline Lee et al. (2004) [51] & Carboplatin & 12 & 35 & $4 / 10(40 \%)$ & 0 & 0 \\
\hline Lee et al. (2005) [53] & Carboplatin & 12 & 127 & $11 / 31(35 \%)$ & $1(0.8 \%)$ & 0 \\
\hline $\begin{array}{l}\text { Hesterberg et al. (2009) } \\
\text { [4] }\end{array}$ & Carboplatin & 8 or 10 & 105 & $13 / 30(43 \%)$ & $1(0.9 \%)$ & 1 \\
\hline Patil et al. (2012) [36] & Carboplatin & 8 or 12 & 148 & $23 / 39(59 \%)$ & 0 & 0 \\
\hline Wong et al. (2014) [14] & Oxaliplatin & 8 or 13 & 200 & $17 / 48(35 \%)$ & $1(0.5 \%)$ & 0 \\
\hline Sloane et. al. (2016) [31] & $\begin{array}{l}\text { Carboplatin } \\
\text { Cisplatin } \\
\text { Oxaliplatin }\end{array}$ & $12-16^{\mathrm{a}}$ & Carboplatin 1069 & $\begin{array}{l}\text { NR; } 253(24 \%) \text { carboplatin } \\
\text { desensitizations had mild } \\
\text { HSR and } 87(8 \%) \text { had } \\
\text { moderate-severe HSR }\end{array}$ & Carboplatin $41(4 \%)$ & 0 \\
\hline $\begin{array}{l}\text { Mawhirt et al. (2018) } \\
\text { [54] }\end{array}$ & $\begin{array}{l}\text { Carboplatin } \\
\text { Oxaliplatin }\end{array}$ & 12 & $146^{\mathrm{b}}$ & $21 / 36(58 \%)^{\mathrm{b}}$ & $3(2 \%)^{\mathrm{b}}$ & NR \\
\hline
\end{tabular}

$B T R$ breakthrough reaction, $N R$ not reported

${ }^{\mathrm{a}} \mathrm{A}$ total of 22 desensitizations were performed that were $<12$ steps

${ }^{b}$ Data is combined for carboplatin and oxaliplatin as results of desensitizations were not distinguished

Comparison of study populations and outcomes for different desensitization protocols is shown in Table 10. The 3-bag 12-step and 4-bag 16-step protocols are the most widely used, having been validated in over 3000 published cases and shown to be effective for chemotherapy agents, monoclonal antibodies, and antibiotics, even in severe HSRs [31, 41, 59]. Grade 3 breakthrough HSRs are extremely rare, occurring in less than $1 \%$ of cases, and over $99 \%$ of desensitizations can be completed despite breakthrough HSRs [5, 31, 32, 41, 60]. Two-bag protocols have been developed for patients with initial mildto-moderate reactions and negative ST, or patients who have tolerated standard 3-bag protocols [4, 14, 32, 36, 60]. One-bag protocols have garnered increasing interest due to ease of preparation and administration, but thus far, studies are limited to smaller numbers of patients and study populations may not be equivalent, especially for more severe initial HSRs.

\section{Four-Step Reintroduction Protocols}

Four-step reintroduction protocols for administration of platins and taxanes have been published, variably labeled as "desensitization" or "graded challenge," and have also not been validated in large studies. These are reminiscent of but distinct from prior reports of extended infusions. Two centers previously studied the use of prophylactic extended carboplatin infusion in patients with recurrent ovarian cancer and no prior history of HSR. They found that the administration of $1 \%, 10 \%$, and $90 \%$ of the total dose, respectively, in three 60-min steps did not decrease rates of subsequent HSR relative to standard infusion [61, 62].

More recent studies using 4-step protocols have raised interest in whether risk stratification based on initial HSR severity and ST results can identify patients who can tolerate shorter protocols. One study that used ST after HSRs identified 21 platinum ST-negative and 12 taxane ST-negative

Table 9 Breakthrough reactions in patients undergoing taxane desensitization

\begin{tabular}{|c|c|c|c|c|c|c|}
\hline Study & Agent & $\begin{array}{l}\text { No. of steps in } \\
\text { desensitization }\end{array}$ & $\begin{array}{l}\text { No. of desensitizations } \\
\text { completed }\end{array}$ & $\begin{array}{l}\text { No. of patients } \\
\text { with BTR }\end{array}$ & $\begin{array}{l}\text { Severe } \\
\text { BTR }\end{array}$ & $\begin{array}{l}\text { No. of patients unable to } \\
\text { complete treatment due } \\
\text { to BTR }\end{array}$ \\
\hline Lee et al. (2005) [53] & $\begin{array}{l}\text { Paclitaxel } \\
\text { Docetaxel }\end{array}$ & 12 & $\begin{array}{l}\text { Paclitaxel } 114 \\
\text { Docetaxel } 2\end{array}$ & $\begin{array}{l}6 / 22(27 \%) \\
0\end{array}$ & NR & 0 \\
\hline Picard et al. (2016) [32] & $\begin{array}{l}\text { Paclitaxel } \\
\text { Docetaxel }\end{array}$ & $8-16$ & 940 & $29 / 138(21 \%)$ & 0 & $0^{\mathrm{a}}$ \\
\hline Otani et al. (2018) [27] & Paclitaxel & $8-17$ & NR & $9 / 30^{\mathrm{b}}(30 \%)$ & 0 & 0 \\
\hline
\end{tabular}

$B T R$ breakthrough reaction, $N R$ not reported

${ }^{a}$ One patient stopped treatment because of adverse reaction with paclitaxel-induced pneumonitis

${ }^{b}$ Five of 35 patients in the study were rechallenged without desensitization 


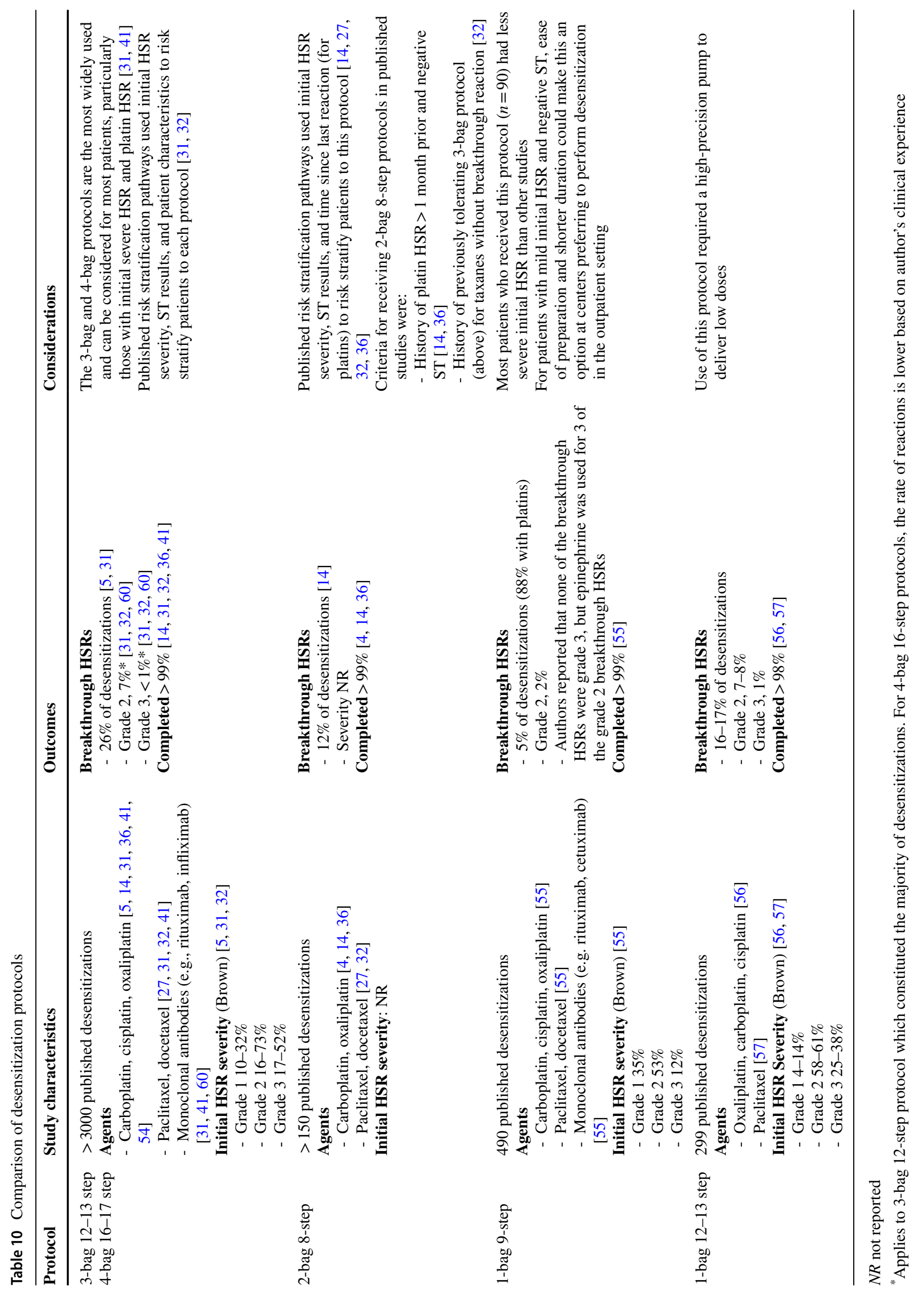


patients who were able to tolerate the same agent via 4-step challenge, as well as others who could tolerate an alternate agent in the same class [39]. However, there are important differences to note about the patient populations studied in 4-step desensitization protocols, especially for platins. The protocol reported by $\mathrm{Li}$ et al. for carboplatin and cisplatin was restricted to patients with mild to moderate low-risk initial HSRs. A later publication found that, when applied to patients with initial moderate (high-risk) HSRs, 4/20 (20\%) experienced severe breakthrough HSRs that prevented treatment completion [58, 63]. The rapid 4-bag, 4-step protocol published by Altwerger et al. included 73/129 (57\%) patients with no prior history of HSR but who had positive skin test results when screened after 6 cycles of carboplatin, which may represent a different population [64]. In addition, there was one death reported in this study, in a patient with underlying pulmonary hypertension who had tolerated multiple previous desensitizations. As a result, careful consideration of risk profiles is needed to determine if and when such protocols can be safely used.

\section{Pathways}

Institutions have developed different pathways for chemotherapy HSR management that incorporate the elements in this review, including grading of reaction severity, skin testing, drug challenge, and desensitization.

The choice of setting and available resources, including nursing-to-patient ratio, may also affect an institution's pathway and the ability to perform certain procedures such as skin testing. Depending on the resources available, desensitizations may occur in the ICU, inpatient acute care ward, outpatient infusion center, or outpatient specialized allergy unit.

Different approaches have been published around the safe reintroduction of platinum agents following HSR. These approaches include use of ST to determine the initial desensitization protocol, with or without serial ST in patients with remote HSR to identify ST conversion as described above [14, 36, 37, 39]. However, routine skin testing can be challenging due to varying institutional regulations and resources, as well as burdensome for patients who are chronically ill and already require frequent healthcare encounters. A more widely acceptable and feasible pathway may be to use a 12-step protocol for patients with initial mild or moderate HSRs and a 16-step protocol for patients with initial severe HSRs [5, 31]. In addition, as the sensitivity of ST for certain agents such as oxaliplatin is not known, desensitization can be offered to patients with or without a positive ST result, regardless of initial HSR severity [5]. For patients with no breakthrough HSR, the same or potentially shorter protocol could be used. For patients who experience breakthrough HSR, the severity of the reaction can guide individualized adjustments to the dilutions, steps, and premedications, or decisions to use a longer protocol.

Similarly, for taxane HSRs, the approach to reintroduction relies on characteristics and grade of initial HSR, as well as ST results if available (Fig. 2) [32]. Challenge can be considered for patients with grade 1 HSRs and negative ST, while patients with grade 2 to 3 immediate HSRs and positive ST undergo desensitization. As with platinum agents, the severity of breakthrough HSRs during desensitization or challenge can guide individualized modifications or decisions to utilize a slower protocol. Patients without breakthrough HSR can advance toward a shorter protocol, challenge, or regular infusion. When ST is not available, institutions can follow the pathway as if patients are STpositive, which enables a more cautious approach, or use grading of the initial HSR severity alone to risk-stratify patients into desensitization protocols of different lengths versus challenge [27].

\section{Discussion}

As this review shows, the optimal use of desensitization protocols in different patient populations and settings is still being tailored. With increasing safety data over time, more patients with mild-to-moderate initial HSRs, and even some with severe initial HSRs, have been desensitized in outpatient infusion centers at institutions experienced with RDD, instead of in the ICU [31]. This has significant advantages in terms of patient access and convenience, ease of scheduling, and resource demands. As pharmacy and nursing resources differ between inpatient and outpatient settings, reports of ongoing experiences in the outpatient setting will add to the literature on safety and efficacy.

The information outlined here is intended to help institutions determine what pathway might best meet their needs. These decisions require consideration of the time and resources required for desensitization, urgency of treatment, and availability of trained staff and standardized protocols for treatment of HSRs. Institution-specific factors may also affect decisions around use of skin testing, drug challenge, and choice of desensitization protocol. For example, serial ST may be more beneficial in situations when advancing from slower to faster desensitization infusions would improve convenience or quality of life for patients-by enabling transition to outpatient slowed infusion at centers where desensitization must occur in the ICU. In contrast, if patients can receive empiric desensitizations in the outpatient infusion center, additional visits for skin testing may not be desired by the patient, even if feasible. As discussed above, institutions differ in terms 


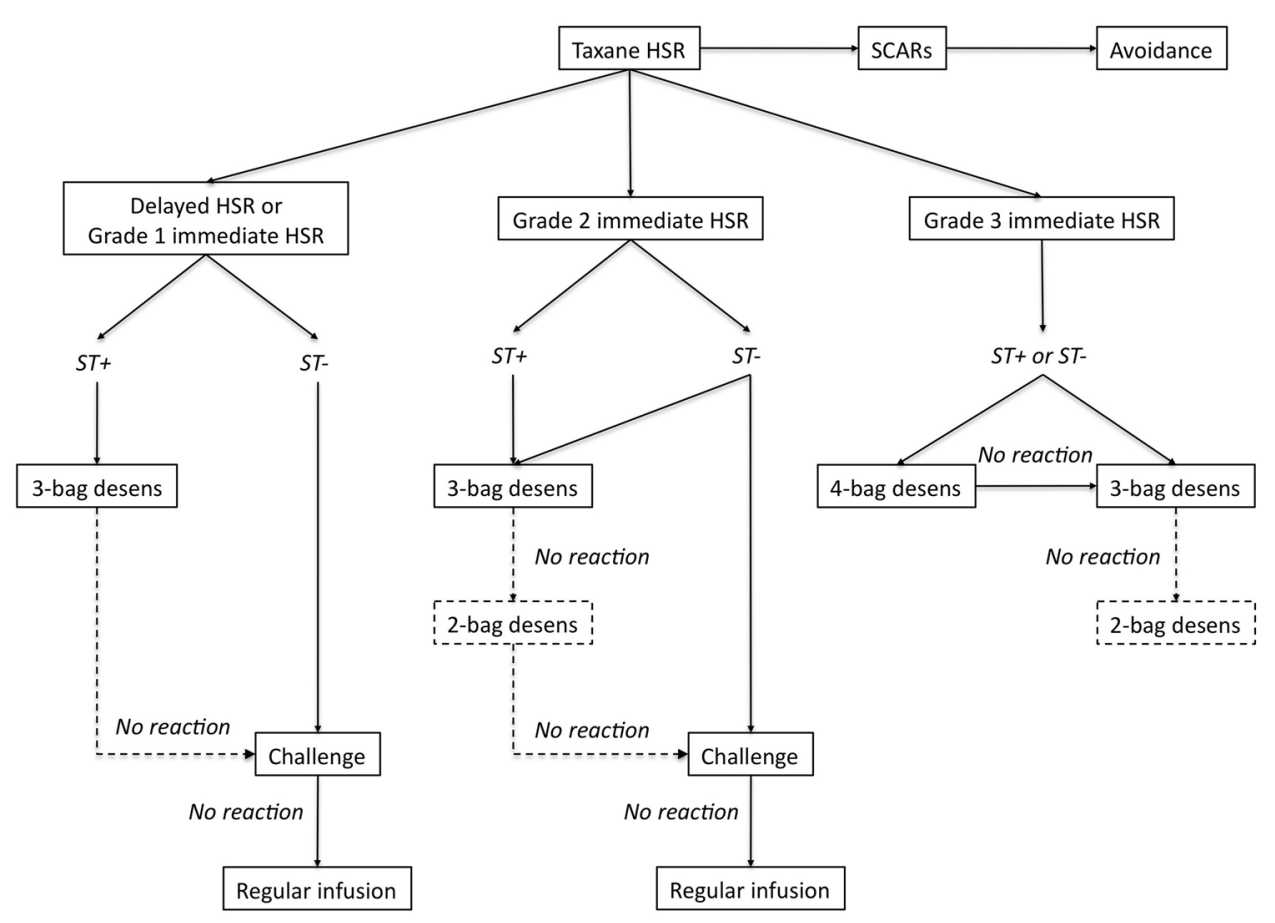

Fig. 2 Approach to reintroduction of taxanes after HSRs. Patients with a history of severe cutaneous adverse drug reactions (SCARs) including Stevens-Johnson syndrome and blistering skin reactions should avoid taxanes. Grading of immediate HSR severity is based on Brown's classification. Patients with delayed or grade 1 immediate HSRs with negative skin testing (ST-) can undergo challenge. The decision to perform desensitization or challenge in patients with grade 2 immediate HSRs who are ST-is based on patient comorbidities and comfort with the procedure. Patients with grade 3 HSRs,

of whether drug challenge is even considered in the initial evaluation for low-risk or ST-negative patients, or only after uneventful desensitizations.

\section{Summary and Conclusions}

The last two decades have witnessed significant advances in our understanding of risk factors, clinical phenotypes, and mechanisms of chemotherapy HSRs, as well as the role of diagnostic tools like skin testing. Desensitization to platinum and taxane agents has been shown to be safe and effective. In addition, RDD seems to be comparable to standard infusion in terms of treatment efficacy. In the largest desensitization study to date, patients with recurrent ovarian cancer receiving carboplatin via desensitization had a nonsignificant trend toward increased life expectancy compared to matched controls receiving standard infusion, suggesting that at the least there is no trade-off in terms of mortality [31]. While drug desensitization has regardless of ST result, undergo desensitization. Institutions that do not have access to ST can follow the protocol for ST + patients. Patients who do not have breakthrough HSRs during the initial protocol can subsequently be treated with a shorter desensitization protocol, challenge, or regular infusion according to the algorithm. For patients who experience breakthrough HSRs, adjustments can be made to premedications and length of protocol. Reproduced from Fig. 1 in Picard et al. [32] with permission

been applied to an increasing number of chemotherapy agents and biologics, there is ongoing interest in the development of better endophenotyping tools and biomarkers to personalize treatment.

Regardless of the pathway chosen, the optimal evaluation and management of patients with chemotherapy HSRs relies on multidisciplinary collaborations between allergy, oncology, pharmacy, nursing, and in some institutions critical care. Chemotherapy desensitizations and drug challenges are high-risk, high-complexity procedures that should be carried out with expert allergy guidance in settings equipped to treat reactions. Standardizing classification systems and research methods will increase knowledge of safe and personalized management strategies for patients and enable institutions to adapt these pathways to their unique needs.

\section{Declarations}

Conflict of Interest The authors declare no competing interests. 
Open Access This article is licensed under a Creative Commons Attribution 4.0 International License, which permits use, sharing, adaptation, distribution and reproduction in any medium or format, as long as you give appropriate credit to the original author(s) and the source, provide a link to the Creative Commons licence, and indicate if changes were made. The images or other third party material in this article are included in the article's Creative Commons licence, unless indicated otherwise in a credit line to the material. If material is not included in the article's Creative Commons licence and your intended use is not permitted by statutory regulation or exceeds the permitted use, you will need to obtain permission directly from the copyright holder. To view a copy of this licence, visit http://creativecommons.org/licenses/by/4.0/.

\section{References}

1. Ledermann JA (2018) First-line treatment of ovarian cancer: questions and controversies to address. Ther Adv Med Oncol 10. https://doi.org/10.1177/1758835918768232

2. Otani IM, Wong J, Banerji A (2017) Platinum chemotherapy hypersensitivity. Immunol Allergy Clin North Am 37:663-677. https://doi.org/10.1016/j.iac.2017.06.003

3. Boulanger J, Boursiquot JN, Cournoyer G, Lemieux J, Masse MS, Almanric K et al (2014) Management of hypersensitivity to platinum- and taxane-based chemotherapy: cepo review and clinical recommendations. Curr Oncol 21:630-641. https://doi. org/10.3747/co.21.1966

4. Hesterberg PE, Banerji A, Oren E, Penson RT, Krasner CN, Seiden MV et al (2009) Risk stratification for desensitization of patients with carboplatin hypersensitivity: clinical presentation and management. J Allergy Clin Immunol 123:1262-1267.e1. https://doi.org/10.1016/j.jaci.2009.02.042

5. Silver J, Garcia-Neuer M, Lynch D-M, Pasaoglu G, Sloane DE, Castells M (2020) Endophenotyping oxaliplatin hypersensitivity: personalizing desensitization to the atypical platin. J Allergy Clin Immunol Pract 8:1668-1680.e2. https://doi.org/10.1016/j.jaip. 2020.02.013

6. Markman M, Kennedy A, Webster K, Elson P, Peterson G, Kulp B et al (1999) Clinical features of hypersensitivity reactions to carboplatin. J Clin Oncol Off J Am Soc Clin Oncol 17:1141. https:// doi.org/10.1200/JCO.1999.17.4.1141

7. Polyzos A, Tsavaris N, Kosmas C, Arnaouti T, Kalahanis N, Tsigris C et al (2001) Hypersensitivity reactions to carboplatin administration are common but not always severe: a 10-year experience. Oncology 61:129-133. https://doi.org/10.1159/000055363

8. Koshiba H, Hosokawa K, Kubo A, Miyagi Y, Oda T, Miyagi Y et al (2009) Incidence of carboplatin-related hypersensitivity reactions in Japanese patients with gynecologic malignancies. Int J Gynecol Cancer 19:460-465. https://doi.org/10.1111/IGC.0b013e3181albf2e

9. Navo M, Kunthur A, Badell ML, Coffer LW, Markman M, Brown $\mathrm{J}$ et al (2006) Evaluation of the incidence of carboplatin hypersensitivity reactions in cancer patients. Gynecol Oncol 103:608-613. https://doi.org/10.1016/j.ygyno.2006.04.002

10. Broyles AD, Banerji A, Barmettler S, Biggs CM, Blumenthal K, Brennan PJ et al (2020) Practical guidance for the evaluation and management of drug hypersensitivity: specific drugs. J Allergy Clin Immunol Pract 8:S16-116. https://doi.org/10. 1016/j.jaip.2020.08.006

11. Moon DH, Lee J-M, Noonan AM, Annunziata CM, Minasian L, Houston N et al (2013) Deleterious BRCA1/2 mutation is an independent risk factor for carboplatin hypersensitivity reactions. Br J Cancer 109:1072-1078. https://doi.org/10.1038/bjc. 2013.389
12. Joly F, Ray-Coquard I, Fabbro M, Donoghoe M, Boman K, Sugimoto A et al (2011) Decreased hypersensitivity reactions with carboplatin-pegylated liposomal doxorubicin compared to carboplatin-paclitaxel combination: analysis from the GCIG CALYPSO relapsing ovarian cancer trial. Gynecol Oncol 122:226-232. https://doi.org/10.1016/j.ygyno.2011.04.019

13. Lax T, Long A, Banerji A (2015) Skin testing in the evaluation and management of carboplatin-related hypersensitivity reactions. J Allergy Clin Immunol Pract 3:856-862. https://doi.org/ 10.1016/j.jaip.2015.07.003

14. Wong JT, Ling M, Patil S, Banerji A, Long A (2014) Oxaliplatin hypersensitivity: evaluation, implications of skin testing, and desensitization. J Allergy Clin Immunol Pract 2:40-45. https:// doi.org/10.1016/j.jaip.2013.08.011

15. Picard M, Castells MC (2015) Re-visiting hypersensitivity reactions to taxanes: a comprehensive review. Clin Rev Allergy Immunol 49:177-191. https://doi.org/10.1007/ s12016-014-8416-0

16. Markman M, Kennedy A, Webster K, Kulp B, Peterson G, Belinson J (2000) Paclitaxel-associated hypersensitivity reactions: experience of the gynecologic oncology program of the Cleveland Clinic Cancer Center. J Clin Oncol Off J Am Soc Clin Oncol 18:102-105. https://doi.org/10.1200/JCO.2000.18.1.102

17. Sendo T, Sakai N, Itoh Y, Ikesue H, Kobayashi H, Hirakawa T et al (2005) Incidence and risk factors for paclitaxel hypersensitivity during ovarian cancer chemotherapy. Cancer Chemother Pharmacol 56:91-96. https://doi.org/10.1007/s00280-004-0924-9

18. Bonamichi-Santos R, Castells M (2018) Diagnoses and management of drug hypersensitivity and anaphylaxis in cancer and chronic inflammatory diseases: reactions to taxanes and monoclonal antibodies. Clin Rev Allergy Immunol 54:375-385. https:// doi.org/10.1007/s12016-016-8556-5

19. Pagani M, Bavbek S, Dursun AB, Bonadonna P, Caralli M, Cernadas J et al (2019) Role of skin tests in the diagnosis of immediate hypersensitivity reactions to taxanes: results of a multicenter study. J Allergy Clin Immunol Pract 7:990-997. https://doi.org/10.1016/j.jaip.2018.09.018

20. Feldweg AM, Lee C-W, Matulonis UA, Castells M (2005) Rapid desensitization for hypersensitivity reactions to paclitaxel and docetaxel: a new standard protocol used in 77 successful treatments. Gynecol Oncol 96:824-829. https://doi.org/10.1016/j. ygyno.2004.11.043

21. Hong DI, Madrigal-Burgaleta R, Banerji A, Castells M, AlvarezCuesta E (2020) Controversies in allergy: chemotherapy reactions, desensitize, or delabel? J Allergy Clin Immunol Pract 8:29072915.e1. https://doi.org/10.1016/j.jaip.2020.08.005

22. Ibrahim NK, Desai N, Legha S, Soon-Shiong P, Theriault RL, Rivera E et al (2002) Phase I and pharmacokinetic study of ABI007, a cremophor-free, protein-stabilized, nanoparticle formulation of paclitaxel. Clin Cancer Res 8:1038-1044

23. Ibrahim NK, Samuels B, Page R, Doval D, Patel KM, Rao SC et al (2005) Multicenter phase ii trial of ABI-007, an albumin-bound paclitaxel, in women with metastatic breast cancer. J Clin Oncol 23:6019-6026. https://doi.org/10.1200/JCO.2005.11.013

24. Gradishar WJ, Tjulandin S, Davidson N, Shaw H, Desai N, Bhar $P$ et al (2005) Phase III trial of nanoparticle albumin-bound paclitaxel compared with polyethylated castor oil-based paclitaxel in women with breast cancer. J Clin Oncol 23:7794-7803. https:// doi.org/10.1200/JCO.2005.04.937

25. Hoffman A, Shahidi F (2009) Paclitaxel and other taxanes in hazelnut. J Funct Foods 1:33-37. https://doi.org/10.1016/j.jff. 2008.09.004

26. Bukacel DG, Bander R, Ibrahim RB (2007) Cross-reactivity between paclitaxel and hazelnut: a case report. J Oncol Pharm Pract 13:53-55. https://doi.org/10.1177/1078155207077926

27. Otani IM, Lax T, Long AA, Slawski BR, Camargo CA, Banerji A (2018) Utility of risk stratification for paclitaxel 
hypersensitivity reactions. J Allergy Clin Immunol Pract 6:1266-1273.e2. https://doi.org/10.1016/j.jaip.2017.08.025

28. O'Malley DM, Vetter MH, Cohn DE, Khan A, Hays JL (2017) Outpatient desensitization in selected patients with platinum hypersensitivity reactions. Gynecol Oncol 145:603-610. https:// doi.org/10.1016/j.ygyno.2017.03.015

29. National Cancer Institute (2017) Common Terminology Criteria for Adverse Events (CTCAE) v5.0. Bethesda, Md: National Cancer Institute. Available from: https://ctep.cancer. gov/protocoldevelopment/electronic_applications/docs/ctcae_ v5_quick_reference_5x7.pdf. Accessed: March 15, 2021

30. Brown SGA (2004) Clinical features and severity grading of anaphylaxis. J Allergy Clin Immunol 114:371-376. https://doi. org/10.1016/j.jaci.2004.04.029

31. Sloane D, Govindarajulu U, Harrow-Mortelliti J, Barry W, Hsu FI, Hong D et al (2016) Safety, costs, and efficacy of rapid drug desensitizations to chemotherapy and monoclonal antibodies. J Allergy Clin Immunol Pract 4:497-504. https://doi.org/10. 1016/j.jaip.2015.12.019

32. Picard M, Pur L, Caiado J, Giavina-Bianchi P, Galvão VR, Berlin ST et al (2016) Risk stratification and skin testing to guide re-exposure in taxane-induced hypersensitivity reactions. J Allergy Clin Immunol 137:1154-1164.e12. https://doi.org/10. 1016/j.jaci.2015.10.039

33. Alvarez-Cuesta E, Madrigal-Burgaleta R, Angel-Pereira D, Ureña-Tavera A, Zamora-Verduga M, Lopez-Gonzalez P et al (2015) Delving into cornerstones of hypersensitivity to antineoplastic and biological agents: value of diagnostic tools prior to desensitization. Allergy 70:784-794. https://doi.org/10.1111/ all. 12620

34. Giavina-Bianchi P, Galvão VR, Picard M, Caiado J, Castells MC (2017) Basophil activation test is a relevant biomarker of the outcome of rapid desensitization in platinum compounds-allergy. $\mathrm{J}$ Allergy Clin Immunol Pract 5:728-736. https://doi.org/10.1016/j. jaip.2016.11.006

35. Moñino-Romero S, Vecillas L de las, Alenazy LA, Labella M, Szépfalusi Z, Fiebiger E et al (2020) Soluble FceRI, IgE, and tryptase as potential biomarkers of rapid desensitizations for platin IgE sensitized cancer patients. J Allergy Clin Immunol Pract 8:2085-2088.e10. https://doi.org/10.1016/j.jaip.2020.01.047

36. Patil SU, Long AA, Ling M, Wilson MT, Hesterberg P, Wong JT et al (2012) A protocol for risk stratification of patients with carboplatin-induced hypersensitivity reactions. J Allergy Clin Immunol 129:443-447. https://doi.org/10.1016/j.jaci.2011.10.010

37. Wang AL, Patil SU, Long AA, Banerji A (2015) Risk-stratification protocol for carboplatin and oxaliplatin hypersensitivity: repeat skin testing to identify drug allergy. Ann Allergy Asthma Immunol 115:422-428. https://doi.org/10.1016/j.anai.2015.07.017

38. Markman M, Zanotti K, Peterson G, Kulp B, Webster K, Belinson J (2003) Expanded experience with an intradermal skin test to predict for the presence or absence of carboplatin hypersensitivity. J Clin Oncol 21:4611-4614. https://doi.org/10.1200/JCO.2003.05.539

39. Pradelli J, Verdoire P, Boutros J, Frin A-C, Follana P, Duquesne $\mathrm{J}$ et al (2020) Allergy evaluation of hypersensitivity to platinum salts and taxanes: a six-year experience. J Allergy Clin Immunol Pract 8:1658-1664. https://doi.org/10.1016/j.jaip.2019.12.032

40. Levin AS, Slawski B, Camargo CA, Banerji A (2020) Platin risk stratification algorithm with modified intradermal skin test protocol. J Allergy Clin Immunol Pract 8:1139-1141. https://doi.org/ 10.1016/j.jaip.2019.08.055

41. Castells MC, Tennant NM, Sloane DE, Ida Hsu F, Barrett NA, Hong DI et al (2008) Hypersensitivity reactions to chemotherapy: outcomes and safety of rapid desensitization in 413 cases. J Allergy Clin Immunol 122:574-580. https://doi.org/10.1016/j. jaci.2008.02.044
42. Hong DIC (2019) Desensitization for allergic reactions to chemotherapy. Yonsei Med J 60:119-125. https://doi.org/10.3349/ymj. 2019.60.2.119

43. Siu SWK, Chan RTT, Au GKH (2006) Hypersensitivity reactions to oxaliplatin: experience in a single institute. Ann Oncol 17:259-261. https://doi.org/10.1093/annonc/mdj042

44. Banerji A, Lax T, Guyer A, Hurwitz S, Camargo CA, Long AA (2014) Management of hypersensitivity reactions to carboplatin and paclitaxel in an outpatient oncology infusion center: a 5-year review. J Allergy Clin Immunol Pract 2:428-433. https://doi.org/ 10.1016/j.jaip.2014.04.010

45. Madrigal-Burgaleta R, Bernal-Rubio L, Berges-Gimeno MP, Carpio-Escalona LV, Gehlhaar P, Alvarez-Cuesta E (2019) A large single-hospital experience using drug provocation testing and rapid drug desensitization in hypersensitivity to antineoplastic and biological agents. J Allergy Clin Immunol Pract 7:618-632. https://doi.org/10.1016/j.jaip.2018.07.031

46. Vázquez-Revuelta P, Martí-Garrido J, Molina-Mata K, LleonartBellfill R, Rey-Salido M, Madrigal-Burgaleta R (2021) Delabeling patients from chemotherapy and biologics allergy: implementing drug provocation testing. J Allergy Clin Immunol Pract 9:17421745.e1. https://doi.org/10.1016/j.jaip.2020.11.021

47. Martí-Garrido J, Vázquez-Revuelta P, Lleonart-Bellfill R, MolinaMata K, Muñoz-Sánchez C, Madrigal-Burgaleta R (2020) Pilot experience using drug provocation testing for the study of hypersensitivity to chemotherapy and biological agents. J Investig Allergol Clin Immunol 31:166-168. https://doi.org/10.18176/ jiaci.0552

48. Madrigal-Burgaleta R, Berges-Gimeno MP, Angel-Pereira D, Ferreiro-Monteagudo R, Guillen-Ponce C, Pueyo C et al (2013) Hypersensitivity and desensitization to antineoplastic agents: outcomes of 189 procedures with a new short protocol and novel diagnostic tools assessment. Allergy 68:853-861. https://doi.org/ 10.1111/all.12105

49. Morales AR, Shah N, Castells M (2005) Antigen-IgE desensitization in signal transducer and activator of transcription 6-deficient mast cells by suboptimal doses of antigen. Ann Allergy Asthma Immunol 94:575-580. https://doi.org/10.1016/S1081-1206(10) 61136-2

50. Sancho-Serra M del C, Simarro M, Castells M. Rapid IgE desensitization is antigen specific and impairs early and late mast cell responses targeting FceRI internalization. Eur J Immunol 2011;41:1004-13. https://doi.org/10.1002/eji.201040810

51. Lee C-W, Matulonis UA, Castells MC (2004) Carboplatin hypersensitivity: a 6-h 12-step protocol effective in 35 desensitizations in patients with gynecological malignancies and mast cell/IgEmediated reactions. Gynecol Oncol 95:370-376. https://doi.org/ 10.1016/j.ygyno.2004.08.002

52. Giavina-Bianchi P, Aun MV, Galvão VR, Castells M (2015) Rapid desensitization in immediate hypersensitivity reaction to drugs. Curr Treat Options Allergy 2:268-285. https://doi.org/10.1007/ s40521-015-0060-2

53. Lee C-W, Matulonis UA, Castells MC (2005) Rapid inpatient/ outpatient desensitization for chemotherapy hypersensitivity: standard protocol effective in 57 patients for 255 courses. Gynecol Oncol 99:393-399. https://doi.org/10.1016/j.ygyno.2005.06.028

54. Mawhirt SL, Fonacier LS, Calixte R, Davis-Lorton M, Aquino MR (2018) Skin testing and desensitization outcomes among platinumsensitive oncology patients. Ann Allergy Asthma Immunol 120:437439. https://doi.org/10.1016/j.anai.2018.01.008

55. Pérez-Rodríguez E, Martínez-Tadeo JA, Pérez-Rodríguez N, Hernández-Santana G, Callero-Viera A, Rodríguez-Plata E et al (2018) Outcome of 490 desensitizations to chemotherapy drugs with a rapid one-solution protocol. J Allergy Clin Immunol Pract 6:1621-1627.e6. https://doi.org/10.1016/j.jaip.2017.11.033 
56. Chung SJ, Kang SY, Kang RY, Kim YC, Lee KH, Kim TY et al (2018) A new non-dilution rapid desensitization protocol successfully applied to all-grade platinum hypersensitivity. Cancer Chemother Pharmacol 82:777-785. https://doi.org/10.1007/ s00280-018-3662-0

57. Lee JH, Moon M, Kim YC, Chung SJ, Oh J, Kang DY et al (2020) A one-bag rapid desensitization protocol for paclitaxel hypersensitivity: a noninferior alternative to a multi-bag rapid desensitization protocol. J Allergy Clin Immunol Pract 8:696-703. https://doi.org/ 10.1016/j.jaip.2019.10.014

58. Vetter MH, Khan A, Backes FJ, Bixel K, Cohn DE, Copeland LJ et al (2019) Outpatient desensitization of patients with moderate (high-risk) to severe platinum hypersensitivity reactions. Gynecol Oncol 152:316-321. https://doi.org/10.1016/j.ygyno.2018.10.037

59. Castells M (2017) Drug hypersensitivity and anaphylaxis in cancer and chronic inflammatory diseases: the role of desensitizations. Front Immunol 8:1472. https://doi.org/10.3389/fimmu.2017.01472

60. Isabwe GAC, Garcia Neuer M, de Las Vecillas Sanchez L, Lynch DM, Marquis K, Castells M (2018) Hypersensitivity reactions to therapeutic monoclonal antibodies: phenotypes and endotypes. $\mathbf{J}$ Allergy Clin Immunol 142:159-170.e2. https://doi.org/10.1016/j. jaci.2018.02.018

61. Lax T, Dizon DS, Birrer M, Long A, Del Carmen M, Goodman A et al (2017) Extended carboplatin infusion does not reduce frequency of hypersensitivity reaction at initiation of retreatment in patients with recurrent platinum-sensitive ovarian cancer. $\mathbf{J}$ Allergy Clin Immunol Pract 5:177-178. https://doi.org/10.1016/j. jaip.2016.07.010

62. LaVigne K, Hyman DM, Zhou QC, Iasonos A, Tew WP, Aghajanian C et al (2018) A randomized trial of prophylactic extended carboplatin infusion to reduce hypersensitivity reactions in recurrent ovarian cancer. Int J Gynecol Cancer 28:1176-1182. https://doi.org/10.1097/IGC.0000000000001280

63. Li Q, Cohn D, Waller A, Backes F, Copeland L, Fowler J et al (2014) Outpatient rapid 4-step desensitization for gynecologic oncology patients with mild to low-risk, moderate hypersensitivity reactions to carboplatin/cisplatin. Gynecol Oncol 135:90-94. https://doi.org/10.1016/j.ygyno.2014.07.104

64. Altwerger G, Gressel GM, English DP, Nelson WK, Carusillo N, Silasi DA et al (2017) Platinum desensitization in patients with carboplatin hypersensitivity: a single-institution retrospective study. Gynecol Oncol 144:77-82. https://doi.org/10.1016/j.ygyno. 2016.09.027
65. Castells M (2017) Diagnosis and management of anaphylaxis in precision medicine. J Allergy Clin Immunol 140:321-333. https:// doi.org/10.1016/j.jaci.2017.06.012

66. Schiavetti A, Varrasso G, Maurizi P, Castello MA (1999) Hypersensitivity to carboplatin in children. Med Pediatr Oncol 32:183185. https://doi.org/10.1002/(sici)1096-911x(199903)32:3\% 3c183::aid-mpo4\%3e3.0.co;2-p

67. Ruggiero A, Rizzo D, Catalano M, Attinà G, Riccardi R (2017) Hypersensitivity to carboplatin in children with malignancy. Front Pharmacol 08. https://doi.org/10.3389/fphar.2017.00201

68. Lafay-Cousin L, Sung L, Carret A-S, Hukin J, Wilson B, Johnston DL et al (2008) Carboplatin hypersensitivity reaction in pediatric patients with low-grade glioma: a Canadian Pediatric Brain Tumor Consortium experience. Cancer 112:892-899. https://doi.org/10. 1002/cncr.23249

69. Koren C, Yerushalmi R, Katz A, Malik H, Sulkes A, Fenig E (2002) Hypersensitivity reaction to cisplatin during chemoradiation therapy for gynecologic malignancy. Am J Clin Oncol 25:625-626. https://doi.org/10.1097/00000421-200212000-00020

70. Pivot X, Koralewski P, Hidalgo JL, Chan A, Gonçalves A, Schwartsmann G et al (2008) A multicenter phase II study of XRP6258 administered as a 1-h i.v. infusion every 3 weeks in taxane-resistant metastatic breast cancer patients. Ann Oncol 19:1547-52. https://doi.org/10.1093/annonc/mdn171

71. de Bono JS, Oudard S, Ozguroglu M, Hansen S, Machiels J-P, Kocak I et al (2010) Prednisone plus cabazitaxel or mitoxantrone for metastatic castration-resistant prostate cancer progressing after docetaxel treatment: a randomised open-label trial. Lancet Lond Engl 376:1147-1154. https://doi.org/10.1016/S0140-6736(10) 61389-X

72. Bracarda S, Gernone A, Gasparro D, Marchetti P, Ronzoni M, Bortolus R et al (2014) Real-world cabazitaxel safety: the Italian early-access program in metastatic castration-resistant prostate cancer. Future Oncol 10:975-983. https://doi.org/10.2217/fon.13. 256

73. Brockow K, Garvey LH, Aberer W, Atanaskovic-Markovic M, Barbaud A, Bilo MB et al (2013) Skin test concentrations for systemically administered drugs-an ENDA/EAACI Drug Allergy Interest Group position paper. Allergy 68:702-712. https://doi. org/10.1111/all.12142

Publisher's Note Springer Nature remains neutral with regard to jurisdictional claims in published maps and institutional affiliations. 